\title{
Pennies from eBay: the Determinants of Price in Online Auctions
}

David Lucking-Reiley

Vanderbilt University

\author{
Doug Bryan and \\ Naghi Prasad \\ Andersen Consulting
}

\author{
Daniel Reeves \\ University of Michigan
}

First Draft: November 1999

\begin{abstract}
This paper presents an exploratory analysis of the determinants of prices in online auctions for collectible one-cent coins at the eBay Web site. Our initial dataset consists of over 20,000 auctions which took place during July and August 1999, which were collected automatically by a "spider" program. From this large data set, we provide a number of descriptive statistics on the patterns in eBay data. We then perform detailed analysis on a restricted sample of 461 mintcondition Indian-head pennies, for which we were able to obtain accurate estimates of book value from a coin-collector's Web site. We have three major findings. First, a seller's feedback ratings, reported by other eBay users, have a measurable effect on her auction prices. Negative feedback ratings have a much greater effect than positive feedback ratings do. Second, minimum bids and reserve prices tend to have positive effects on the final auction price, though this finding does not take into account the fact that these instruments also decrease the probability of the auction resulting in an actual sale. Also, minimum bids appear only to have a significant effect when they are binding on a single bidder's bid, as predicted by economic theory. Third, when a seller chooses to have her auction last for a longer period of days, this significantly increases the auction price on average
\end{abstract}




\section{Introduction}

Since the birth of Web-based auctions in 1995, auctions on the Internet have grown at a tremendous rate. By far the largest consumer-oriented auction site is eBay, which in 1998 had over one billion dollars in transactions. At a growth rate of more than $10 \%$ per month, eBay is likely to have over three billion dollars in transactions in $1999 .{ }^{1}$ Individual sellers register their items for eBay's automated auctions, and individual consumers bid on the items. Its size places eBay among the largest Internet retailers in the world, possibly even the single largest one. ${ }^{2}$ According to Nielsen Netratings, over seven million unique individuals visit the site each month, and consumers' average time spent browsing the site is considerably higher at eBay than at any other major Web site (twice as much as at Yahoo!, seven times as much as at Amazon). ${ }^{3}$ Over three million individual auctions close at eBay every week, representing an unprecedented amount of economic auction activity.

Online auctions represent a rich environment for study. Despite much interest in auction theory over the past two decades, empirical studies of auctions have been limited by data availability. Most of the empirical literature on auctions looked exclusively at government auctions (oil drilling rights, logging rights, procurement auctions), and the data collection process has been a very labor-intensive one. ${ }^{4}$ However, the emergence of eBay and other online auctions now makes it possible to obtain data from a wide variety of auction markets. (eBay currently has over two thousand unique categories of items, from vintage Star Wars action figures to rare automobiles to digital cameras.) In this paper, we demonstrate an automated method to quickly

\footnotetext{
${ }^{1}$ See Lucking-Reiley [1999] for more details on the transaction volume at eBay and 140 other online auction sites.

${ }^{2}$ Stores, National Retail Federation, September 1999, http://www.stores.org/99top100int_1.html

${ }^{3}$ Neilsen Netratings Reporter, Nielsen Media Research and NetRatings, Inc., http://nielsen-netratings.com/, October 1999.

${ }^{4}$ See Hendricks and Paarsch [1995] for a survey of past empirical research on auctions.
} 
assemble a large set of auction data directly from eBay, and we conduct an exploratory study of the determinants of prices in eBay auctions. ${ }^{5}$

To collect our data, we created a "spider" - a piece of software designed to "crawl" over eBay's Web pages and collect information on each auction. In a matter of hours, the spider collected comprehensive data on 20,000 auctions of U.S. collectible pennies auctioned at eBay during July and August, $1999 .{ }^{6}$ We present descriptive statistics for these auctions, as well as a regression analysis of factors which affect prices in these auctions.

\section{Institutional Details of eBay Auctions}

A great deal of information on eBay auctions is publicly available. Anyone may view the listings of the items for sale, and in fact, all listings remain publicly available on eBay's site for at least one month after they close. Figure 1 displays an example of a bidding page for an eBay auction; our spider collects its data by visiting pages just like this one and extracting the pertinent information from them.

An individual auction on eBay lasts between three and ten days. All eBay auctions use an ascending-bid (English) format, with the twist that there is a fixed end time and date set by the seller instead of a going-going-gone ending rule. This has caused many bidders to hold back their bids until the final seconds of the auction, so that they won't reveal to others how high they are willing to bid. To counteract this tendency, eBay installed a "proxy bidding" system that issues bids on the buyer's behalf. When bidding, buyers may specify the maximum bid they would submit for an item. The system keeps this amount private, bidding on the buyer's behalf at just

\footnotetext{
${ }^{5}$ Bajari and Hortacsu [1999] also perform an analysis of the determinants of price in eBay auctions, using a different data set of coin auctions (mint and proof sets, rather than individual cents). The focus of their paper is a structural model to distinguish between private-value and affliated-value paradigms, but they also present some reduced-form regression results using a smaller set of variables than the one we use. For those variables which our studies have in common, the results appear to be broadly consistent between the two papers.
} 
one increment over the next highest bid, until it reaches the buyer's specified maximum bid. This provides the convenience of a Vickrey auction, where bidders do not need to engage in constant monitoring of the auction, and where the winner's price is determined by the second-highest bidder. Because the earlier bid wins in the case of a tie, this procedure restores some incentive for bidders to submit bids early. Many bidders make use of the proxy-bidding feature, though others persist in submitting bids at the very last minute. ${ }^{7}$

When a seller lists her goods or services for auction at eBay, she provides both a short title and a long description of the item. Bidders see the short titles when browsing lists of items up for auction, and the long description after they click on the short title of a particular item in order to view the bidding page for that auction. The seller may also choose to place digital photographs of the item online as part of the auction description. When a photograph is included, the auction's title is listed with an icon that indicates that a photo is available. For example, Figure 2 is the photograph included in the description of the auction listed in Figure 1.

The seller also chooses a number of parameters to specify how the auction will run. She may set the opening bid amount wherever she wishes. (The default is $\$ 0.01$.) She may also set a secret "reserve price," such that if the highest bid remains below the reserve, the seller will not conduct the transaction with the high bidder. The seller may also choose the length of her auction: three, five, seven, or ten days. The auction starts as soon as the seller registers it at eBay, so the day and time when the auction starts and ends are controlled by the seller. One of the central questions of this paper is whether and how these parameters affect the auction price.

\footnotetext{
${ }^{6}$ It is a trivial matter to adapt the spider to collect data for other categories of auctions. In fact, during the course of a week, our spider collected data on approximately one million auctions in various other categories. For concreteness, we focus exclusively on the penny data in this paper.

${ }^{7}$ Two possible reasons for bidding at the last minute are: (1) bidders hope to get an item at a low price against an unsophisticated bidder who would be willing to bid high, but doesn't understand either proxy bidding or the ability to submit bids at the very last minute, or (2) bidders fear cheating by the eBay system, lying to the winner about the amount of the second-highest bid. The first reason seems much more common than the second, as no evidence has yet surfaced of eBay cheating in this manner. See LuckingReiley [2000] for more details about eBay proxy bidding, and its precursors in stamp auctions over the past century.
} 
The seller pays two different types of fees to eBay. The first is a nonrefundable insertion fee, paid for the service of listing the item. The insertion fee ranges from $\$ 0.25$ to $\$ 2.00$, depending on the minimum bid and reserve price chosen. Then, after the auction concludes, the seller also pays a "final value fee" to eBay as a percentage of the selling price. This commission equals $5 \%$ of the first $\$ 25$ of the selling price, plus $2.5 \%$ of the remaining value up to $\$ 1000$, plus $1.25 \%$ of any amount over $\$ 1000$. If the item does not receive any bids above the seller's reserve price, then the item does not sell and no final value fee is assessed. ${ }^{8}$

eBay has a well-publicized reputation mechanism designed to make buyers and sellers feel comfortable conducting transactions with each other, exchanging cash and goods by mail with people they've never met. Under this system, buyers and sellers have the opportunity to rate each other as positive $(+1)$, neutral $(0)$, or negative $(-1)$, and the cumulative total is displayed on the site as a Feedback Rating for that user. ${ }^{9}$ Any time a user is identified on the site (either as the seller or a bidder in an auction), his Feedback Rating number is displayed in parentheses. Users with ratings higher than 10 receive a "star," a graphic icon whose color changes to indicate larger and larger rating numbers. ${ }^{10}$ Some sellers have accumulated Feedback Ratings in excess of 10,000. Anyone whose rating goes below -4 is prohibited from using the site any further. In addition to the numeric ratings, users may view the entire list of feedback comments left by other users about any individual. Typical examples of positive comments are:

-Quick turnaround. Item arrived in excellent condition •smooth transaction...no problems here!! THANX!!"

Negative comments can be even more informative:

-Sent money out and after 2 months still have not received the items I purchased -Dishonest seller. Beware!! I had to file a fraud claim. It has been upheld. -Prestige set did not come in box or with papers as advertised.

\footnotetext{
${ }^{8}$ Recently, eBay has developed separate fee structures for automobiles and real estate. The fee structures described here apply to all other items.

${ }^{9}$ At most one positive and one negative rating from each unique individual are counted in the total. Thus the most that an individual can affect another's rating is \pm 1 .

${ }^{10}$ At this writing, the "star" categories in use represent ratings of 10-99; 100-499; 500-999; 1,000-9,999; and 10,000 or higher.
} 
Many observers have identified the feedback-rating system as the key to eBay's success.

An example is the following excerpt from a Business Week article:

[eBay founder] Pierre M. Omidyar... hit on the idea of building a flea market in cyberspace - where people could buy and sell anything to anybody. There was one snag, though. How could he persuade complete strangers to trust one another enough to hand over merchandise or cash without ever having met? Omidyar's solution was to devise a system where buyers and sellers can rate their experiences with different traders... That provided the assurance people needed to feel comfortable trading with one another - and it helped Omidyar's eBay become the largest person-to-person auction site on the Web. ${ }^{11}$

Not only do business observers repeatedly make such observations, but eBay itself also clearly considers its feedback ratings to be a key asset. When rival Amazon started its similar auction-listing service in spring 1999, it initially provided a method for users to import their existing feedback ratings from eBay. EBay protested vigorously, claiming that the feedback ratings were eBay property. In response, facing the possibility of a legal challenge, Amazon discontinued the rating-import service.

Despite the fact that conventional wisdom says that feedback ratings are essential on eBay, we are not aware of any empirical evidence which confirms this. And there are good economic reasons, often overlooked by the popular press, why these feedback ratings might not have much impact after all. First, any user can provide a rating point to any other user at any time; eBay does not require the user to have conducted a transaction with the person she is rating. The discussion board at the AuctionWatch Web site often features complaints by individuals about others who abuse the feedback system at eBay in various ways. For example, a buyer might give negative feedback ratings to a seller merely because he doesn't like the merchandise she's advertising for sale. Or a seller might, in retaliation, negatively rate each buyer that negatively rates them. Further, a seller might convince dozens of friends to give him individual positive ratings, making her look like an experienced, reputable seller before she has ever participated in her first auction. In addition, there is a potential free-rider problem: when a buyer 
conducts a transaction, he gets very little personal benefit for doing so - the public-good benefit accrues to the people who will later be looking at the rating. Especially if a transaction goes well, there may be very little motivation for the parties to rate each other positively. If users are not motivated to take the time to provide feedback on every transaction, then the rating numbers might be meaningless, dominated by the manipulations of people trying to subvert the spirit of the system, and no one should pay attention to them. Clearly, there are some honest users who participate actively and honestly for the benefit of the community, but there are also some who abuse and manipulate the ratings. It is an empirical question whether the first group dominates the second. If ratings really have an important economic impact, then we should expect to see sellers with high positive feedback attracting more bidders and higher prices than sellers with lower feedback ratings, all else being equal. One of the questions of this paper is whether eBay's feedback ratings really do have a measurable economic impact.

\section{Description of the Data}

The data for this study were collected by a "spider" written in the programming language Perl, running on a UNIX workstation. We chose to focus on the eBay category "U.S. cents," because this was a category with a wide variety of well-categorized goods with a wide variety of prices. Our spider proceeded as follows. It visited the eBay home page and extracted the link to the "Coins \& Stamps" page. Then it visited the Coins \& Stamps page and extracted the link to US Cents. The US Cents page is where the listing of current auctions begins. About 150 auctions are listed on this page. The page also contains links to about 100 other pages, each listing 50 current auctions of U.S. 1-cent coins. The US Cents page also contains a link to "completed" auctions. Our spider followed this link to a listing of the U.S. Cent auctions that closed on the previous day. That page listed the first 50 such auctions, and included links to similar pages listing the remaining U.S. Cent auctions that closed on the previous day. By

\footnotetext{
${ }^{11}$ Source: Green and Browder [1998].
} 
traversing these pages are spider collected the IDs of the auctions that closed on the previous day. Further, the "completed" page contained a link to auctions that closed two days earlier, and that page contained a link to auctions that closed three days earlier, and so on. By traversing this path our spider collected the IDs of all US Cent auctions that closed in previous month. Once we had the auction IDs, another spider used them to retrieve details about each auction.

Each auction ID was used to construct a Web URL (universal resource locator). That is, IDs like 207495617 were added to Web addresses to form new addresses like http://cgi3.ebay.com/aw-cgi/eBayISAPI.dll?ViewBids\&item=207495617. In effect, the URL is a query to eBay's databases for information about auction number 207495617. The Web page created by eBay in response to the query contains details of the specific auction, including last bid (if any), opening and closing time and date, seller's ID and rating, minimum bid, number of bids, and a listing of bid history. The bid history contains information on each bidder, including buyer's ID and rating, as well as the price, time and date of bids. The spider that collected data on individual auctions collected buyer and seller IDs. Using these IDs another spider could then collect more detailed information about participants.

The third spider collected feedback information on sellers, based on their IDs. Again a URL containing an ID was used. For example, the feedback information about seller "iras4" is generated using the following URL:

<http://cgi2.ebay.com/aw-cgi/eBayISAPI.dll?ViewFeedback\&userid=iras4>.

Figure 3 displays an example feedback page for an eBay member. It includes the number of positive, neutral and negative ratings received. It also contains this data for three recent time periods: the past 7 days, the past month and the past six months. The page also includes (but are not shown in Figure 3) comments made by other members.

We collected data on U.S. Cent auctions held at eBay over a 30-day period during July and August of 1999. Our spiders collected more than 20,292 observations. In this paper we refer to these as the large data set. A subset of these observations were used in the models presented 
later. For the models, we limited the data to auctions of U.S. Indian Head pennies minted between 1859 and 1909, where only one coin was being sold, and where the year and condition of the coin was clearly stated. All these coins were mint state (MS) with grades of between 60 and 66 on a 70-point scale. There were 461 such auctions and we refer to these as the small data set. Using the year and grade, we then manually collected estimated value, or book value, for each coin in the small data set. ${ }^{12}$ Our analysis began with the following data for each observation (variable names that are used in models presented later are given in all capital letters):

- The year of the coin

- The grade of the coin

- The coin's estimated value (BOOKVAL)

- The minimum bid of the auction (MINBID)

- The last bid of the auction (PRICE). If no bids were made then this is the same as the minimum bid.

- $\quad$ The number of bids made (\#BIDS)

- Whether a reserve price was used (RESERVE); 1 if a reserve was used, else 0.

- The length of the auction in days, namely 3, 5, 7 or 10 (NUMDAYS).

- The date and time when the auction opened

- The ID of the seller

- The ID of the winning buyer (if any)

- The number of members who gave the seller a positive rating (a.k.a. unique positives)

- The number of members who gave the seller a negative rating (a.k.a. unique negatives)

- The overall rating of the seller (i.e., unique positives minus unique negatives)

- The seller's total number of positive ratings received (POS)

- The seller's total number of negative ratings received (NEG)

\footnotetext{
${ }^{12}$ Book values where obtained from Collector's Universe (http://collectors.com/).
} 
- The number of neutral ratings received by the seller

- The number of ratings received by the seller that were changed to neutral because the reviewer is no longer a member of eBay's trading community.

Additionally the following variables were derived from the others:

- Whether the auction closed on a Saturday or Sunday (WEEKEND); 1 if so else 0.

- $\quad$ Whether NUMDAYS = 5 (DAYS5)

- $\quad$ Whether NUMDAYS = 7 (DAYS7)

- Whether NUMDAYS = $10($ DAYS10)

Chart 1 shows the number of auctions that closed each day in the large data set. The dip at July $21^{\text {st }}$ was caused by an eBay outage. ${ }^{13}$ The eBay servers were down for more than an hour. Whenever this happens it is eBay's policy to delay the closing of all auctions one day. Thus, practically no auctions closed on the $21^{\text {st }}$.

Charts 2 and 3 show the arithmetic mean of the price of the auctions closing on each day. The spike on Chart 2 is due to five auctions with prices over $\$ 1000$. Chart 3 is the same as Chart 2, with these five outlyers removed. Mean prices are shown for auctions that received at least one bid (the solid line) and for auctions that transacted (the dashed line). Generally auctions with bids have a higher price than auctions that transacted. This might be caused by the use of high reserve prices for expensive items, and thus fewer expensive items transacting.

Chart 4 displays the percentage of auctions that received no bids, and the percentage that had bids but did not meet their reserve. Overall $60-70 \%$ of the 20,000 auctions transacted.

Chart 5 is a histogram of auction closings by day-of-the-week. As one might expect for a consumer-oriented site like eBay, volume is heaviest on weekends. Chart 6 shows volume by the hour of the day and again, as conventions wisdom might indicate, we see that volume is highest in the evening. Here the highest volume is during the 6 P.M. hour, U.S. Pacific time-zone.

\footnotetext{
13 "eBay suffers outage despite assurances," Tim Clark, CNet News.com, July 22, 1999, http://news.cnet.com/news/0-1007-200-345242.html
} 
Charts 7 and 8 show mean prices by day-of-week and hour-of-the-day. Here again we see a spike due to the five auctions that were over $\$ 1000$. Again we see that auctions that transacted have a lower average price than auctions that received bids.

Charts 9 and 10 show the same auction classes as Chart 4 . Here auctions are grouped by the day of the week that they closed (Chart 9) and the hour of the day that they closed (Chart 10). The charts basically show the same trends as Chart 4 , namely, that about $65 \%$ of auctions lead to a transaction. Chart 10 shows that more than $50 \%$ of the auctions that close between 2 A.M. and 4 A.M. receive no bids.

Chart 11 displays a histogram of auctions by auction length. Most auctions, over $60 \%$, are seven days in length, while only $12 \%$ are the maximum length of 10 days. As we will show later, there is evidence that sellers should select longer auction lengths.

Chart 12 groups auctions by the number of bids they received. As shown earlier, more than $20 \%$ received no bids. Over $90 \%$ received less than 20 bids, but there was one auction that received more than 90 bids.

Next, Chart 13 groups auctions by the rating of the seller. The X-scale here is non-linear. It begins increasing by 1 unit, then 10 units, 100 units and finally 1000 units. The chart indicates that more than $20 \%$ of sellers have a rating between 100 and 200, while less than $10 \%$ have a rating between 200 and 300. Our large data set contained nearly 7000 sellers and 3500 buyers who and the high bid in at least one auction. $92 \%$ of the sellers held just one auction during the moth we collected our data, while $45 \%$ of the buyers were highest bidder in just one auction.

Chart 14 displays a histogram of the ratio of minimum bid to book value for the 461 auctions in our small data set. (Here again the X-scale is non-linear.) The chart indicates that many sellers seem to be using the default minimum bid (\$0.01), while about $40 \%$ are setting a minimum bid around $60 \%$ of book value. Chart 15 shows the ration of price to book value for the 285 auctions that transacted. Here again we see a clustering around a ratio of 0.6. In general, U.S. Cents seem to be selling on eBay for $60 \%$ of their book value. 
Our small data set of 461 observations includes 134 unique sellers and 181 unique buyers. 127 of the auctions (28\%) received no bids. 49 auctions (11\%) received bids but had reserve prices that were not met. Thus 285 of the auctions $(62 \%)$ resulted in a transaction. The following table gives descriptive statistics for selected fields:

\begin{tabular}{|c|c|c|c|c|}
\hline & mean & std. dev. & $\min$ & $\max$ \\
\hline BOOKVAL & 277.77 & 541.68 & 21 & 5200 \\
\hline POS & 383.74 & 351.63 & 0 & 1992 \\
\hline NEG & 1.90 & 2.94 & 0 & 19 \\
\hline MINBID & 134.80 & 362.80 & 0.01 & 3500 \\
\hline PRICE & 173.20 & 362.96 & 4.99 & 3500 \\
\hline \#BIDS & 5.15 & 6.26 & 0 & 39 \\
\hline RESERVE & 0.25 & 0.43 & 0 & 1 \\
\hline NUMDAYS & 6.11 & 1.89 & 3 & 10 \\
\hline
\end{tabular}

As in the large data set, sellers most often chose seven days for auction length: 221 (48\%) of the auctions were seven days long. Ten days was the least often selected, with only 41 (9\%) of the auctions running for 10 days.

\section{The Empirical Determinants of eBay Auction Prices}

Table 1 displays regression results on the determinants of prices in the eBay coin auctions in our sample. In each regression, the dependent variable is the natural logarithm of the final price obtained in each auction. Note that when an auction has a reserve price, this observed auction price might not actually result in a transaction, in those cases where the reserve price was not met. We include all observations, whether the reserve price was met or not, in order to get as much information as possible on the factors which influence the outcome of the auction price mechanism. Also, note that nearly $30 \%$ of the auctions had no bids at all. In such cases, we consider the price variable to be censored at the minimum bid level (the latent auction price could not be observed, because the minimum bid amount was set too high). We use a censored-normal 
maximum-likelihood estimation procedure, exactly like a standard Tobit regression except that the censoring point (the minimum bid level) is different across observations.

In the first column, we present regression results for the full set of 20,292 cent auctions. In general, we do not know anything about the average market value for the coins in this dataset, so the BOOKVAL variable is omitted from this regression. This regression gives results which look quite peculiar: in particular, the POS coefficient has a negative sign and the NEG coefficient has a positive sign, and both are statistically significant. This would indicate that a seller's cumulative positive feedback ratings tend to decrease the price she can earn in an auction, while negative feedback tends to increase the price. These turn out to be spurious results caused by omitted variable bias. ${ }^{14}$ On average, sellers with higher feedback ratings appear to be auctioning more low-value pennies, and this causes the spurious negative correlation. To correct for this bias, we next focus on a smaller sample of coins: 461 uncirculated Indian cents for which we were able to obtain book values from the Coin Universe Web site. These book values take into account the coin's date, its rated condition (MS-60 to MS-70) of the coin, and its color (red, red/brown, brown), all of which have important effects on the appraised list value of the coin.

The second, third, and fourth regressions present results for this sample of 461 uncirculated Indian cents, including the log of book value included as an additional regressor. The log-book-value coefficient is 0.81 , statistically significantly lower than 1 , which indicates that higher-valued coins' auction prices tend to be relatively lower fractions of book value. In these regression models, the coefficient estimates for the reputation variables do have the expected signs. This result is robust across all specifications we tried, including a number with other functional forms not reported in the table.

\footnotetext{
${ }^{14}$ Deltas [1999] also illustrates the estimation problems inherent in exploring the determinants of auction price without an appropriate measure of each auctioned item's average value to bidders.
} 
Result 1. A $1 \%$ increase in the seller's positive feedback ratings yields a $0.03 \%$ increase in the auction price, on average. The effect of negative feedback ratings is much larger, and in the opposite direction: a $1 \%$ increase causes a $0.11 \%$ decrease in auction price, on average. The effect of negative feedback is statistically significant at the $5 \%$ level, while the effect of positive feedback is not.

In our initial modeling efforts, we did not separate positive from negative rating points, but instead used eBay's Feedback Rating score, namely the difference between the two numbers, which is reported by eBay in parentheses every time it identifies a user. This variable had no statistically significant effects on price. We conclude that eBay users do not react significantly to eBay's Feedback Rating summary measure, but instead focus mainly on negative rating points. We also note that the disparity in the effects of positive and negative rating points is consistent with findings in risk management ${ }^{15}$ and marketing. ${ }^{16}$

Our second finding, also robust across all model specifications we have tried, is that the length of the auction (in days) positively influences the auction price. Models 2 and 4 show results using the log of the number of days as a regressor, while Model 3 models the number of days as a qualitative variable $(3,5,7$, or 10 days).

Result 2. Longer auctions tend to fetch higher prices. The elasticity of auction price with respect to number of days is +0.06 , and is statistically significant at the 5\% level. 3-day auctions and 5day auctions yield approximately the same prices on average. 7-day auction prices are approximately $24 \%$ higher and 10 -day auctions are $42 \%$ higher, on average, with both effects statistically significantly different from zero.

\footnotetext{
${ }^{15}$ Slovic, P., Risk perception and trust, in V. Molak (ed.), Fundamentals of Risk Analysis and Risk Management, pg. 233—45, Lewis Publishers, 1996.

${ }^{16}$ Haskett, James L., et al., The Service Profit Chain: How Leading Companies Link Profit and Growth to Loyalty, Satisfaction, and Value, Free Press, 1997.
} 
We have more than once heard eBay enthusiasts give the advice that to maximize the final auction price, a seller should schedule her auction to close on the weekend. The rationale is that most bidding activity occurs in the final hours or minutes of an auction, and participation rates are higher on weekends, when people have more leisure time. To investigate the soundness of this advice, we added a WEEKEND dummy variable in model 3. Our results were rather negative: the point estimate indicates that weekend auction revenues are $7 \%$ higher than weekday auction revenues on average, but this difference is not significantly different from zero at the 5\% level.

Our third major result concerns minimum bids and reserve prices. In models 2 through 4 , we find that the presence of a reserve price increases the auction price by about $15 \%$ on average., and the effect is statistically significant. We also find that as the minimum bid increases by $1 \%$, the auction price increases by less than $0.01 \%$ on average, and the effect is not statistically significant. That is, minimum bids and reserve prices both tend to increase the auction price, but the effect of the minimum bid is relatively small.

We were initially puzzled to see that reserve prices affected price positively, because we thought the presence of a reserve price might deter bidder entry. The presence of an unknown reserve price (whose presence, though not the amount, can be seen by bidders) reduces the probability that the winning bid will actually result in a transaction. Thus, the presence of a reserve price may cause some bidders not to bother bidding in the first place, because it might not be worth the effort. However, our regression results in models 2 through 4 indicate an increase, rather than a decrease, in auction price when a reserve price was in effect.

We realized that an important reason why the reserve price may increase the final auction price is that the reserve acts as if it were another competing bidder, at least until the reserve has been met. A concrete example may better illustrate this idea. If a bidder submits a proxy bid of 
$\$ 100$ when the highest bid by someone else is $\$ 50$, his bid will be executed as $\$ 55$ in the absence of a reserve price. In the presence of an $\$ 80$ reserve price, however, that same $\$ 100$ bid will be executed as $\$ 80$ instead of $\$ 55$. It is possible that this is the major source of the reserve-price effect found in our regression. Unfortunately, the available data from eBay make it very difficult to say anything about the seller's optimal reserve price level, because we observe only the presence of the reserve price, and not its magnitude.

By contrast, we do observe the levels of the public minimum bids. And with minimum bids, auction theory has a clear prediction to make. In an English auction with privately known bidder values, the level of the minimum bid should increase prices only in those cases where it is binding on the winning bidder - that is, only in those cases where one person bids.

To examine how the effects of the reserve price and the minimum bid change when the number of bidders changes, we present models 5 and 6 in Table 1 . Model 5 restricts the Indiancent sample to only those auctions with at least one bid, while Model 6 restricts the sample even further to those auctions with at least two bids. With at least one bid, the minimum-bid coefficient becomes four times as large as before, and also becomes statistically significant. Minimum bids can have no positive effect on price in auctions where there are no bids, so it makes sense that the average effect goes up when excluding such auctions. With at least two bids, the effect decreases in size again, and is no longer statistically significant, consistent with the zero effect predicted by theory (competition between at least two bidders causes the minimum bid to be nonbinding, and its level irrelevant).

As for the reserve price, its estimated coefficient is only half as large in the restricted samples as in the full sample. For the case of at least one bid received, the minimum-bid effect goes up, apparently taking away some of the effect previously attributed to the reserve price in the full sample. For the case of at least two bids received, the effect goes up again somewhat, but remains statistically insignificant.

We summarize our findings on minimum bids and reserve prices as follows: 
Result 3. The presence of a reserve price and the level of the minimum bid both have positive estimated effects on the final auction price, though not always statistically significant. In confirmation of economic theory, the level of the minimum bid has a significant positive effect for auctions with only one bidder, but an insignificant effect when there are two or more bidders.

The number of bids clearly matters as a determinant of the auction price, but we chose not to include it as a regressor in the above models because it is endogenously determined by the bidder choices. Instead, we have estimated some regression models with the number of bids as the dependent variable, in order to see what are the factors which cause more entry by bidders. We don't have time to present these results here in detail in this draft, but the general results are similar to those of the price regressions. The number of bids increases with book value (elasticity $=2$ ), decreases with the minimum bid level (elasticity $=-2.3$ ), does not change significantly (perhaps increases slightly) with the presence of a reserve price, increases with the number of

positive seller ratings, decreases with the number of negative seller ratings, and increases with the length of the auction.

\section{Concluding Remarks}

We don't have time to write a full set of concluding remarks in this draft. However, we wish to emphasize the following key points of our paper:

1. eBay and other online auctions represent rich new sources of data for studying empirical behavior in auctions.

2. Large amounts of data can be gathered quickly from eBay using a "spider." 
3. Regressions with auction price as a dependent variable give very misleading results unless an accurate measure of market value or "book value" can be found as a control variable.

4. Longer auctions on eBay tend to attract more bidders and earn higher prices.

5. Reserve prices and minimum bids tend to have positive effects on the auction price, but the overall effect of these seller strategies is hard to determine, given that the use of these instruments sometimes causes the good not to sell at all.

6. Minimum bids increase auction price when they are binding, but have no significant effect when there are two or more bidders. This is consistent with a standard model of bidding up to one's reservation value in an English auction.

7. Seller reputaton points on eBay have a measurable effect on auction prices, but not necessarily in the way that the eBay's summary Feedback Rating might suggest. Rather than positive and negative feedback points being weighted equally, we find that negative ratings matter considerably more than positives. 


\section{References}

Bajari, Patrick, and Ali Hortacsu, "A Structural Model of Internet Auctions." Working paper, Stanford University, 1999.

Deltas, George. "Auction Size and Price Dynamics in Sequential Auctions." Working paper, University of Illinois, 1999.

Green, Heather, and Seanna Browder, "Online Merchants: Cyberspace Winners: How They Did It," Business Week, 22 June 1998, page 154.

Lucking-Reiley, David, “Auctions on the Internet: What's Being Auctioned, and How?” Working paper, Vanderbilt University, 1999.

Lucking-Reiley, David, "Vickrey Auctions Predate Vickrey," Journal of Economic Perspectives, forthcoming, 2000. 
Figure 1. An example eBay auction Web page.

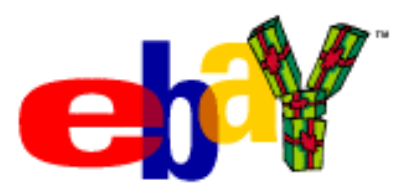

\section{Browse \\ item view}

home | my eBay. | site map

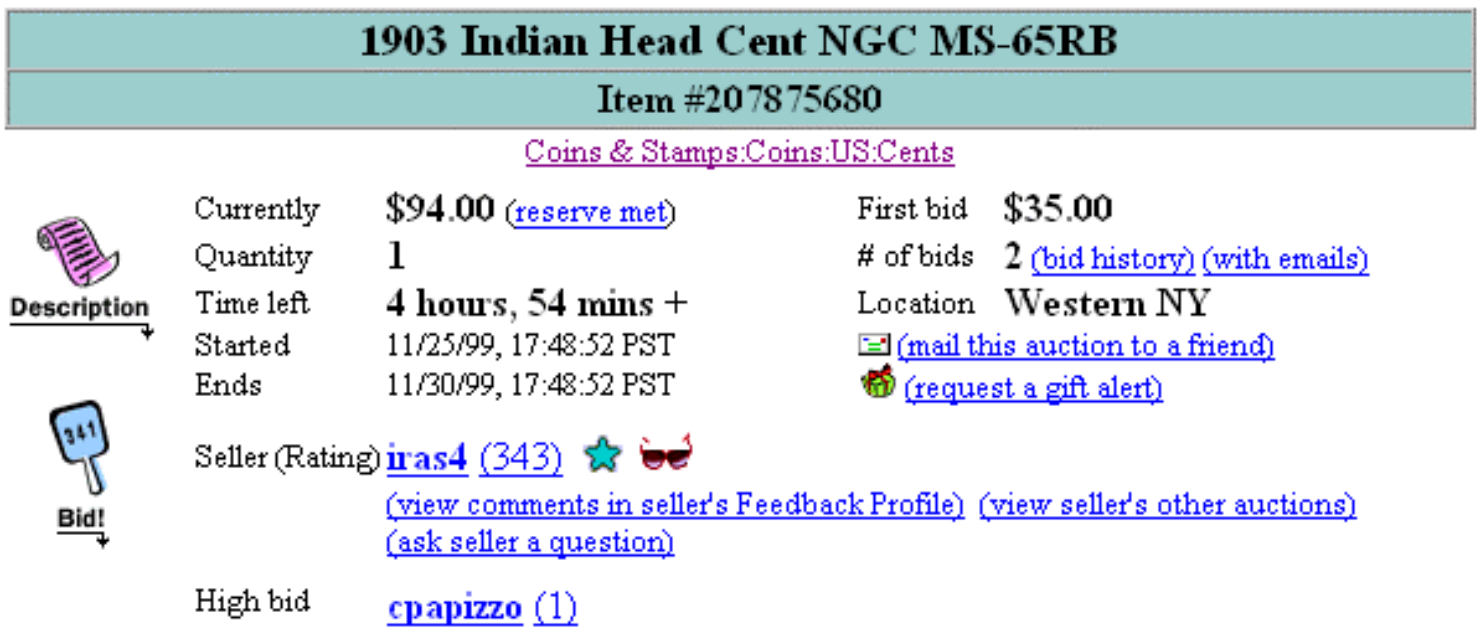

Figure 2. An example auction item photograph.

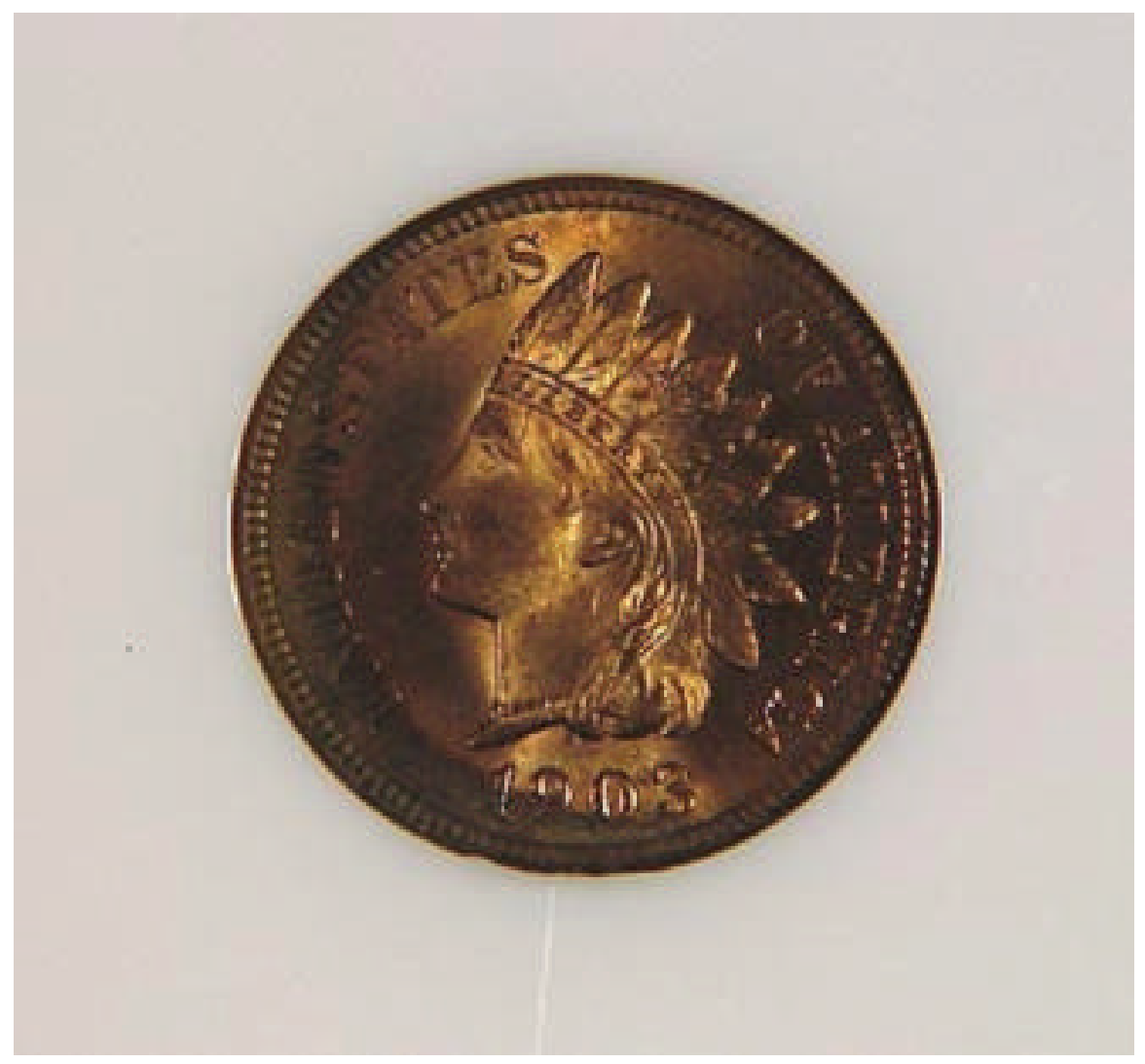


Figure 3. An example feedback page for an eBay seller.

\section{Overall profile makeup}

393 positives. 343 are from unique users and count toward the final rating.

3 neutrals. 3 are from users no longer registered.

$\mathbf{0}$ negatives. $\mathbf{0}$ are from unique users and count toward the final rating.

\section{ebV ID card \\ iras4 $(343)$ \\ Member since May 17, 1998}

Summary of Most Recent Comments

$\begin{array}{lccc} & \text { Past 7 days } & \text { Past month } & \text { Past 6 mo } \\ \text { Positive } & 1 & 14 & 133 \\ \text { Neutral } & 0 & 0 & 0 \\ \text { Negative } & 0 & 0 & 0 \\ \text { Total } & \mathbf{1} & \mathbf{1 4} & \mathbf{1 3 3}\end{array}$

Auctions by iras 4

Note: There are 3 comments that were converted to neutral because the commenting users are no longer registered.

Chart 1. VolumePerDate.xls

\section{Number of penny auctions closing per day}

Dave, I've included GIF versions of the charts but will also indicate the Excel file name in red by the chart caption.

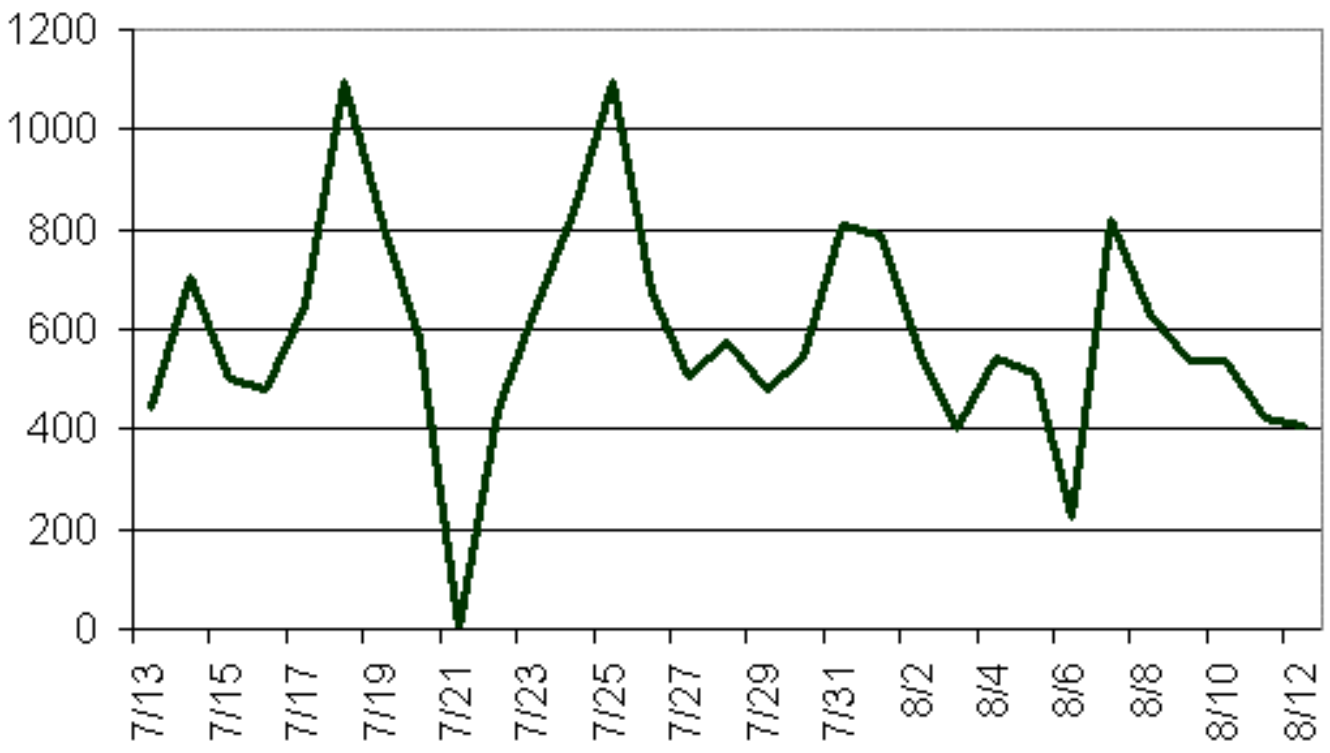


Chart 2 chart 1 of PricePerDate2.xls

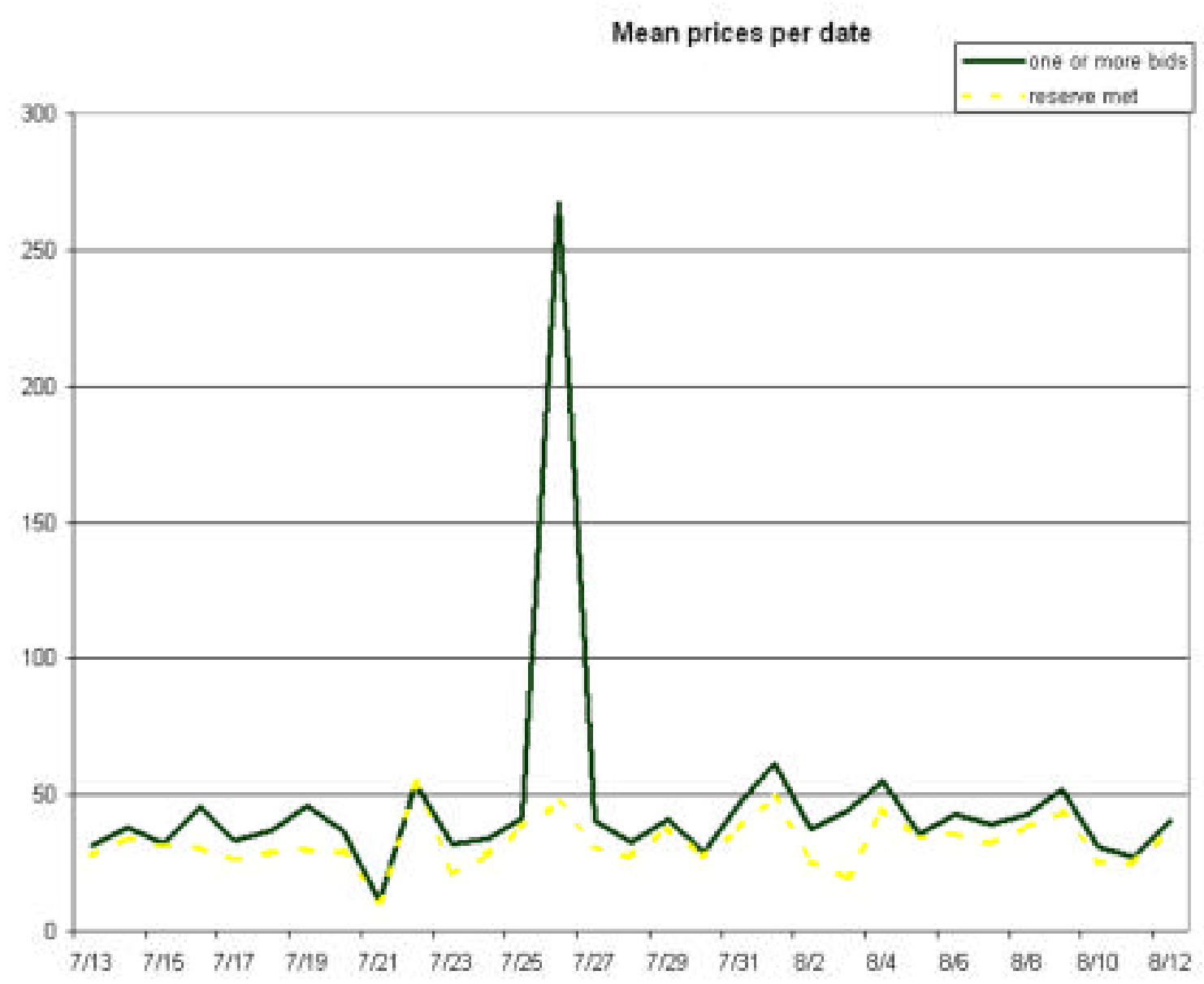


Chart 3 chart2 of PricePerDate2.xls

Mean prices per day (outlyers removed)

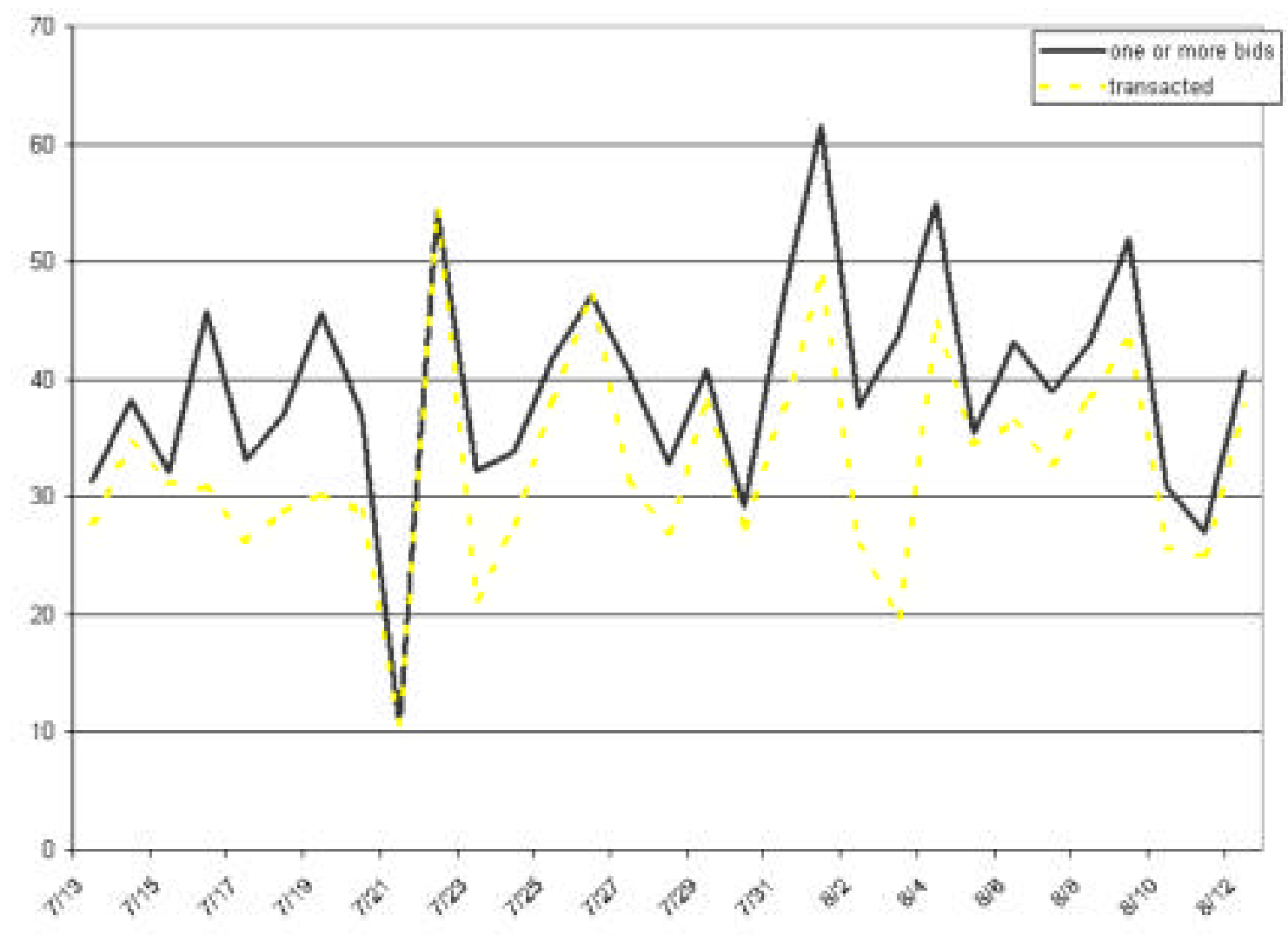




\section{Chart 4 RiskPerDate2}

Stacked pereentages of auctions that received no bids and that did not meet a reserve price

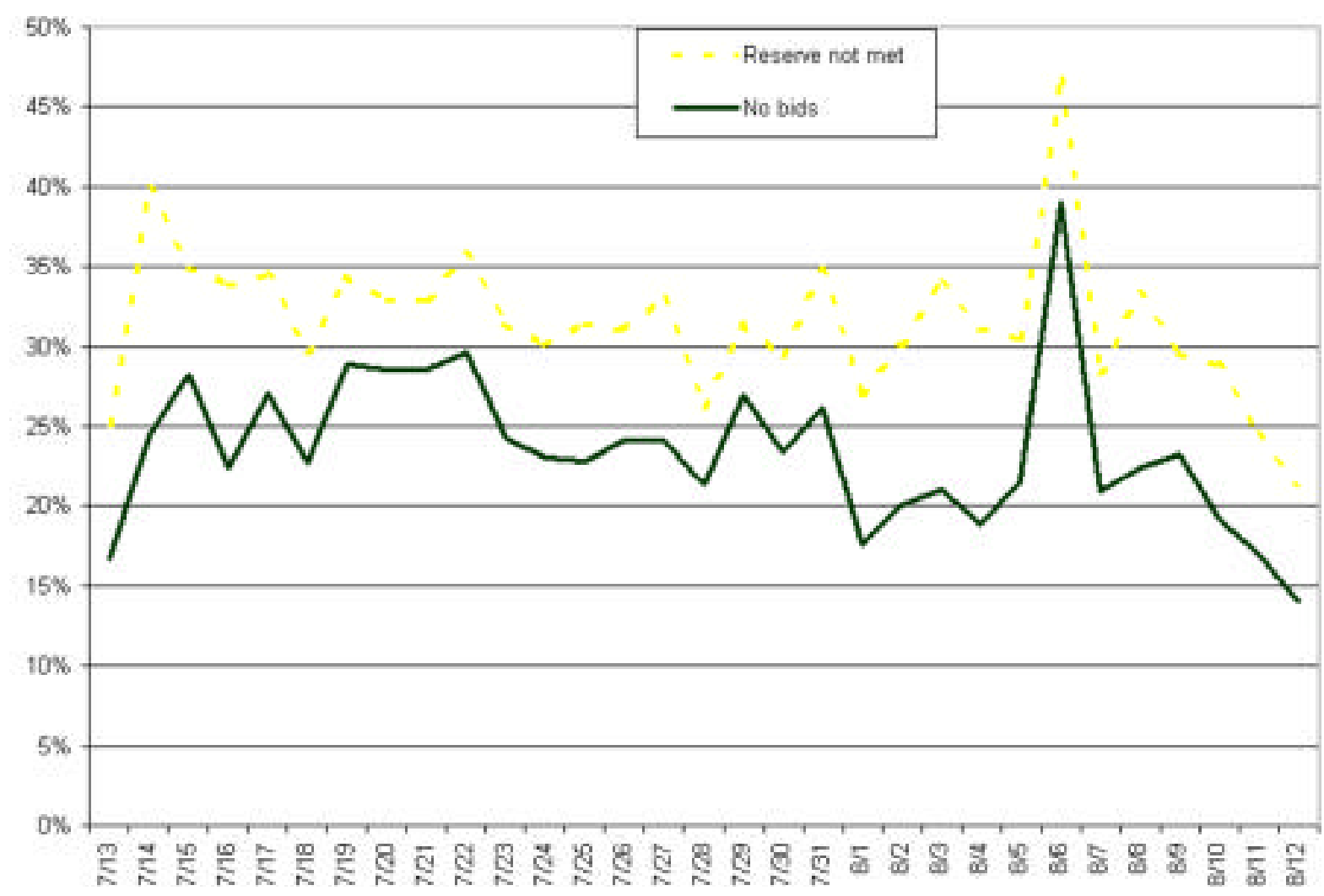


Chart 5. Volume by day of the week.

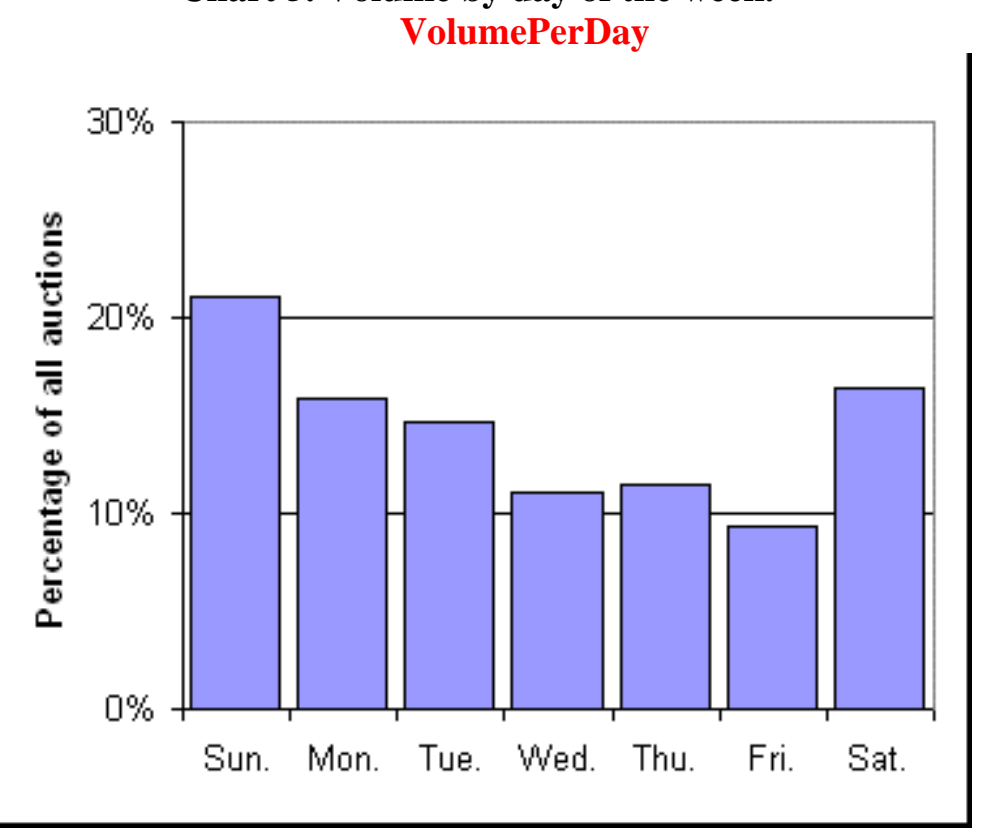

Chart 6. Volume by hour of the day. VolumePerHour

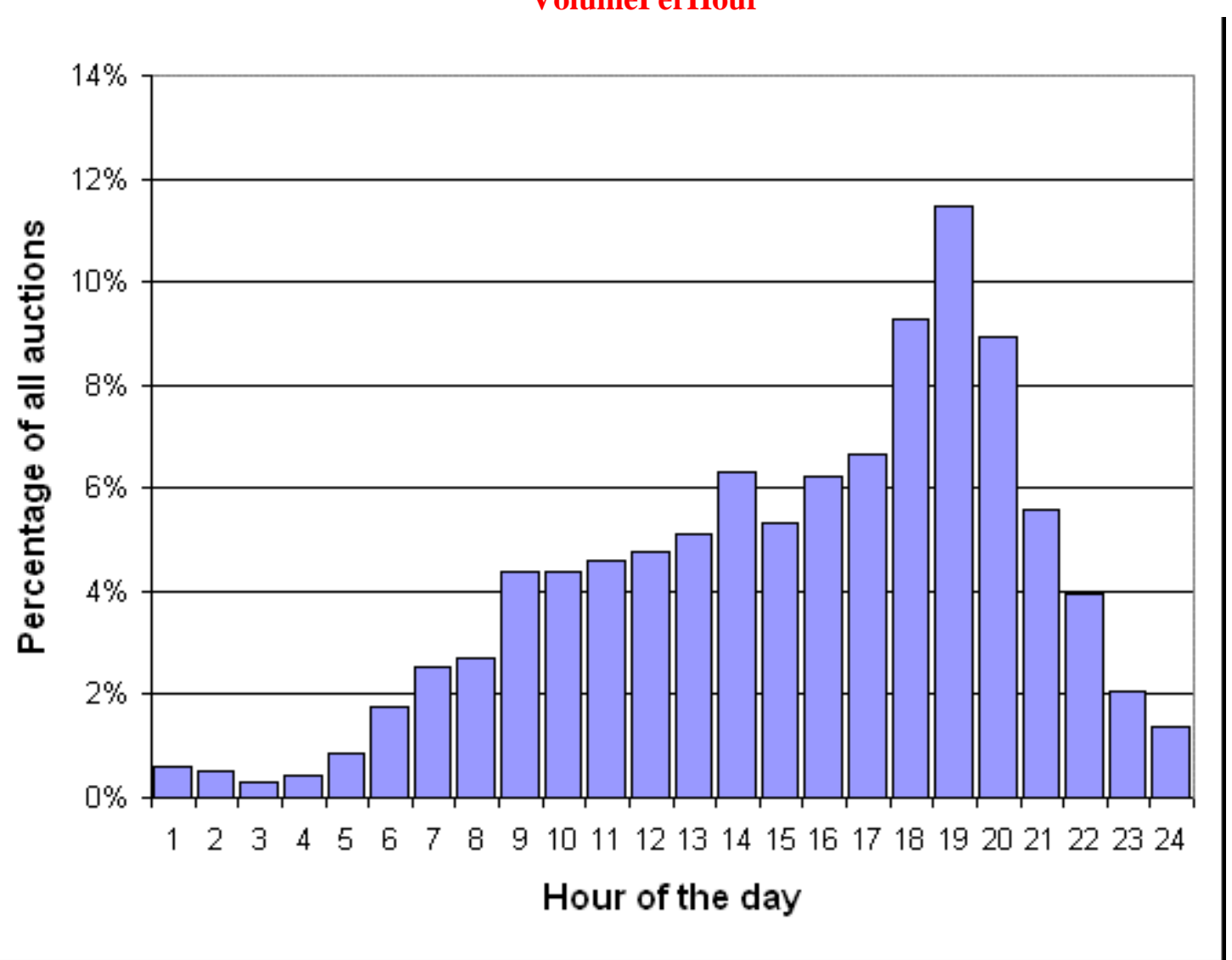




\section{Chart 7 PricePerDay2}

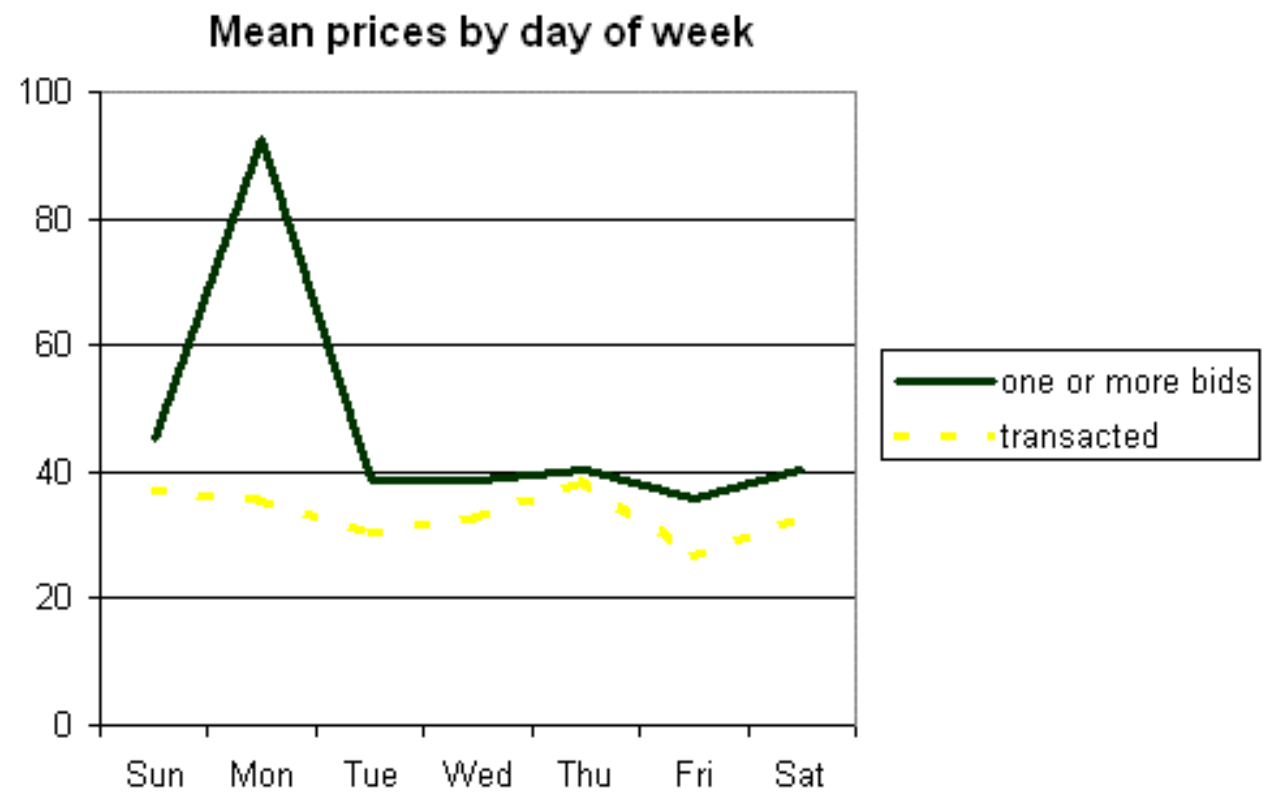




\section{Chart 8 PricePerHour2}

Mean price by hour of the day

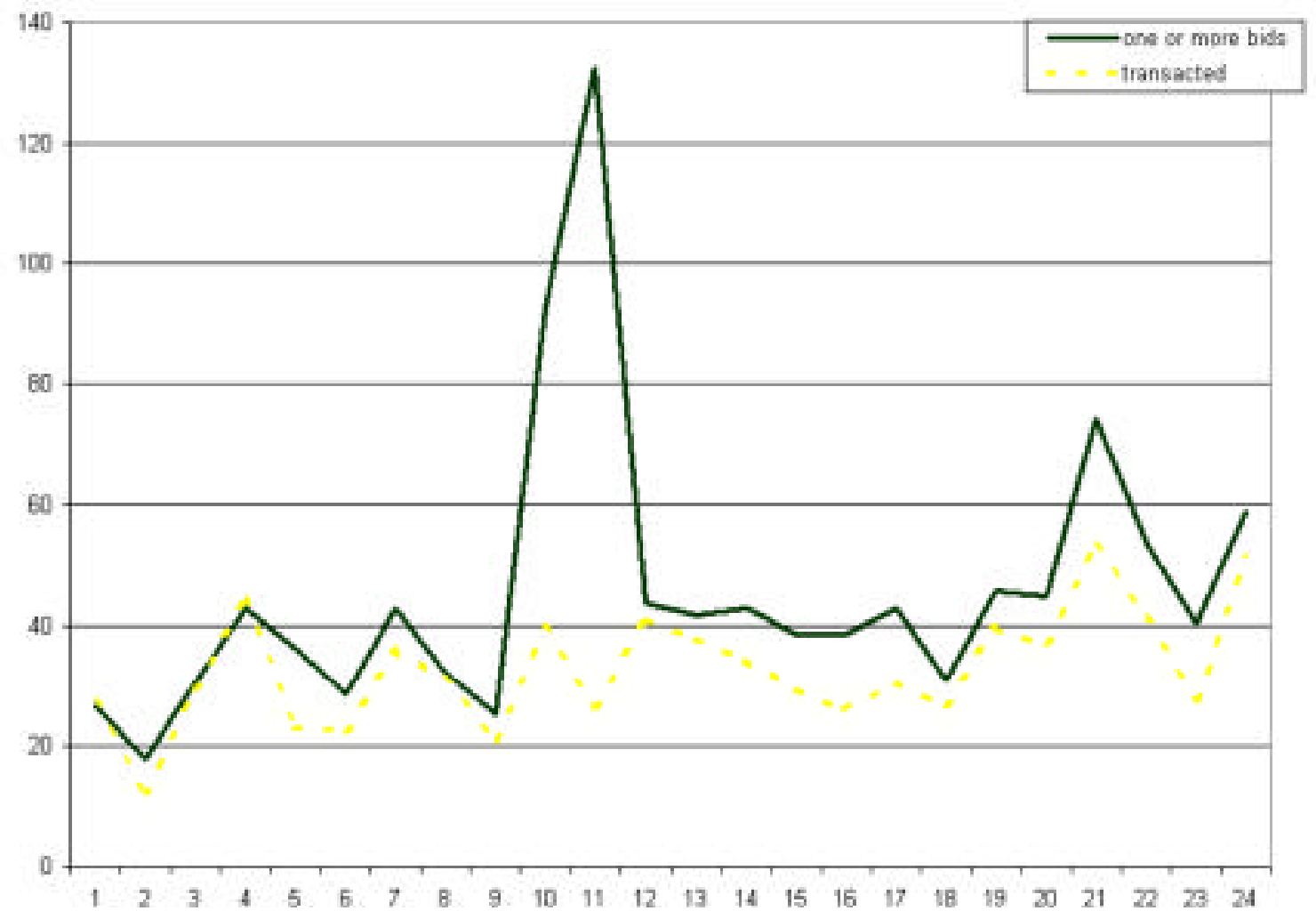


Chart 9 RiskPerDay2

Stacked percentages of auctions that received no bids and that did not met reserve

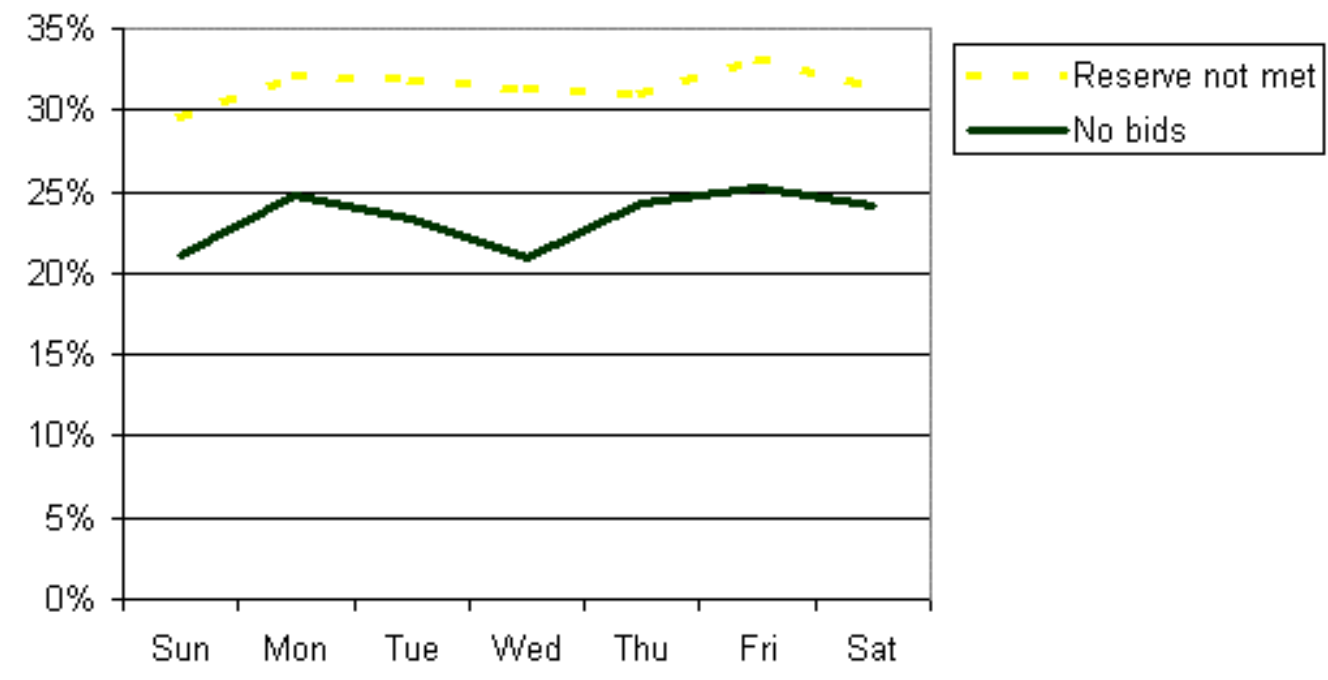




\section{Chart 10 RiskPerHour2}

Stacked percentage of auctions that received no bids and did not met a reserve, by hour of the day

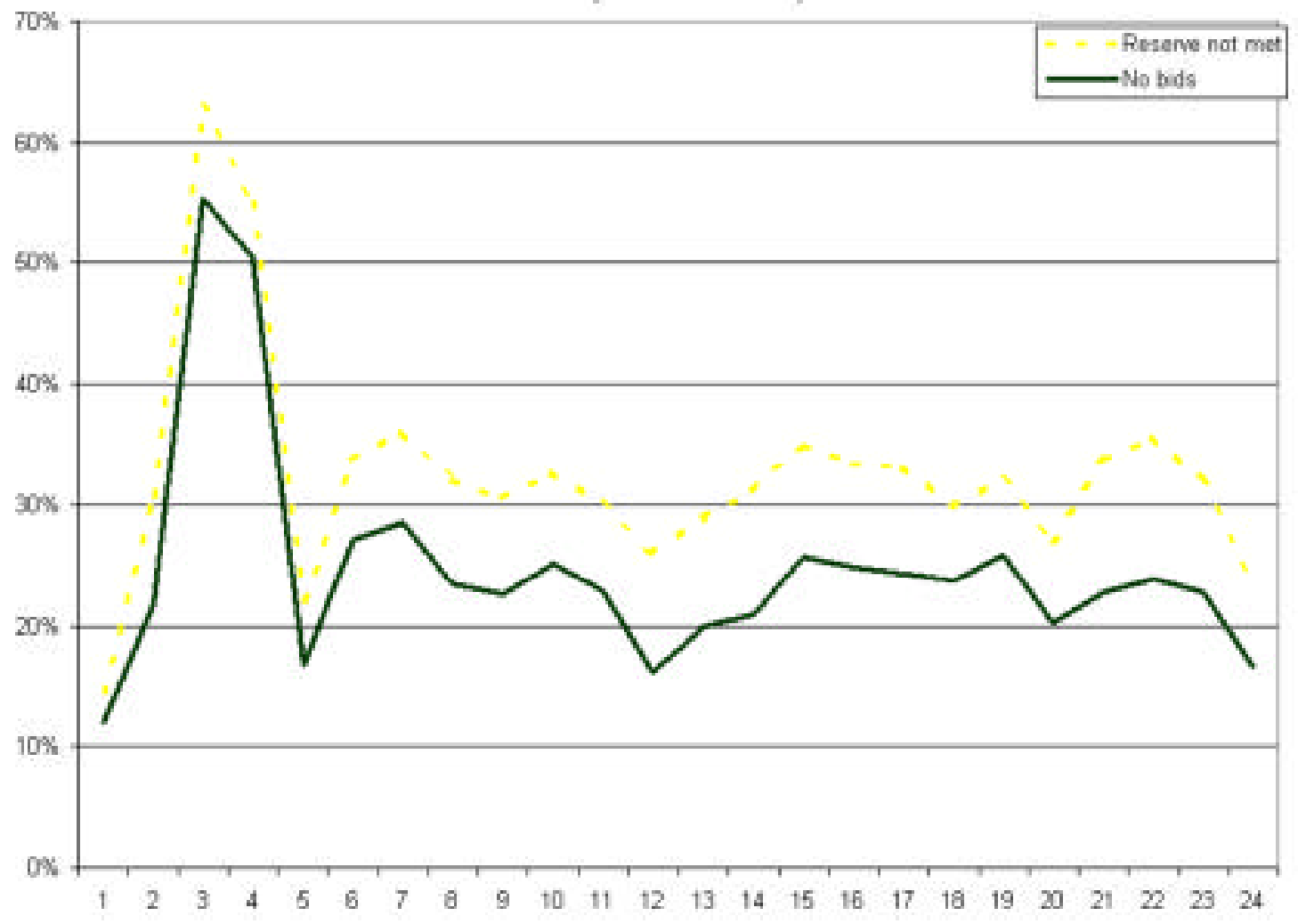


Chart 11. Histogram of auction length, for 20,000 U.S. Cent auctions auctionLenghthiso

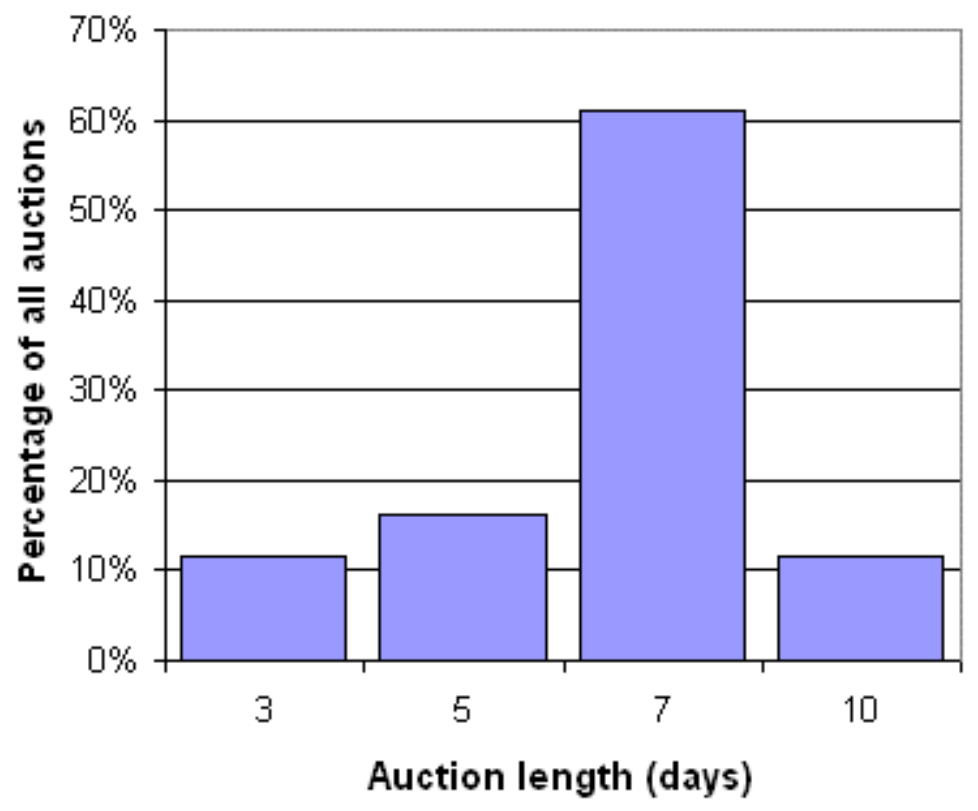

Chart 12 numBidsHisto

Histogram of number of bids received, for

20,000 U.S. Cent auctions

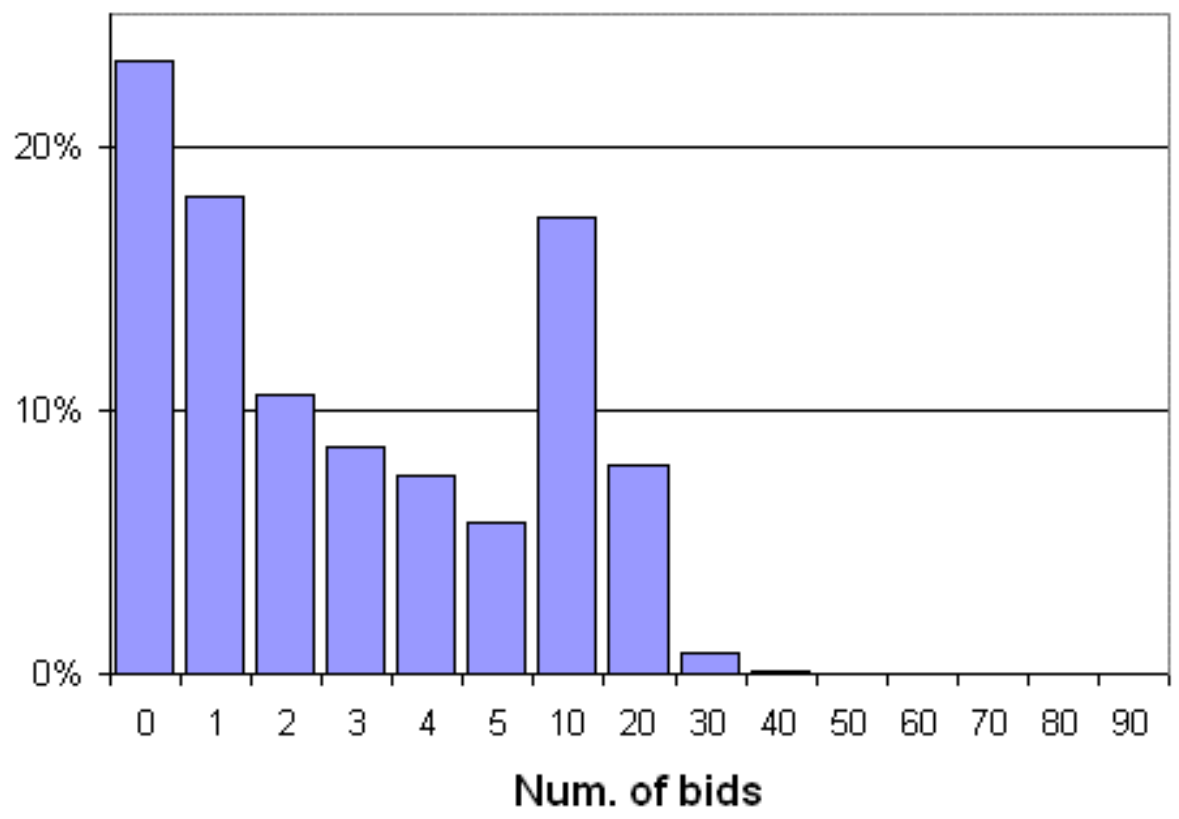




\section{Chart 13 ratingHisto}

Histogram of auctions by seller's reputation, for 20,000 U.S. Cent auctions

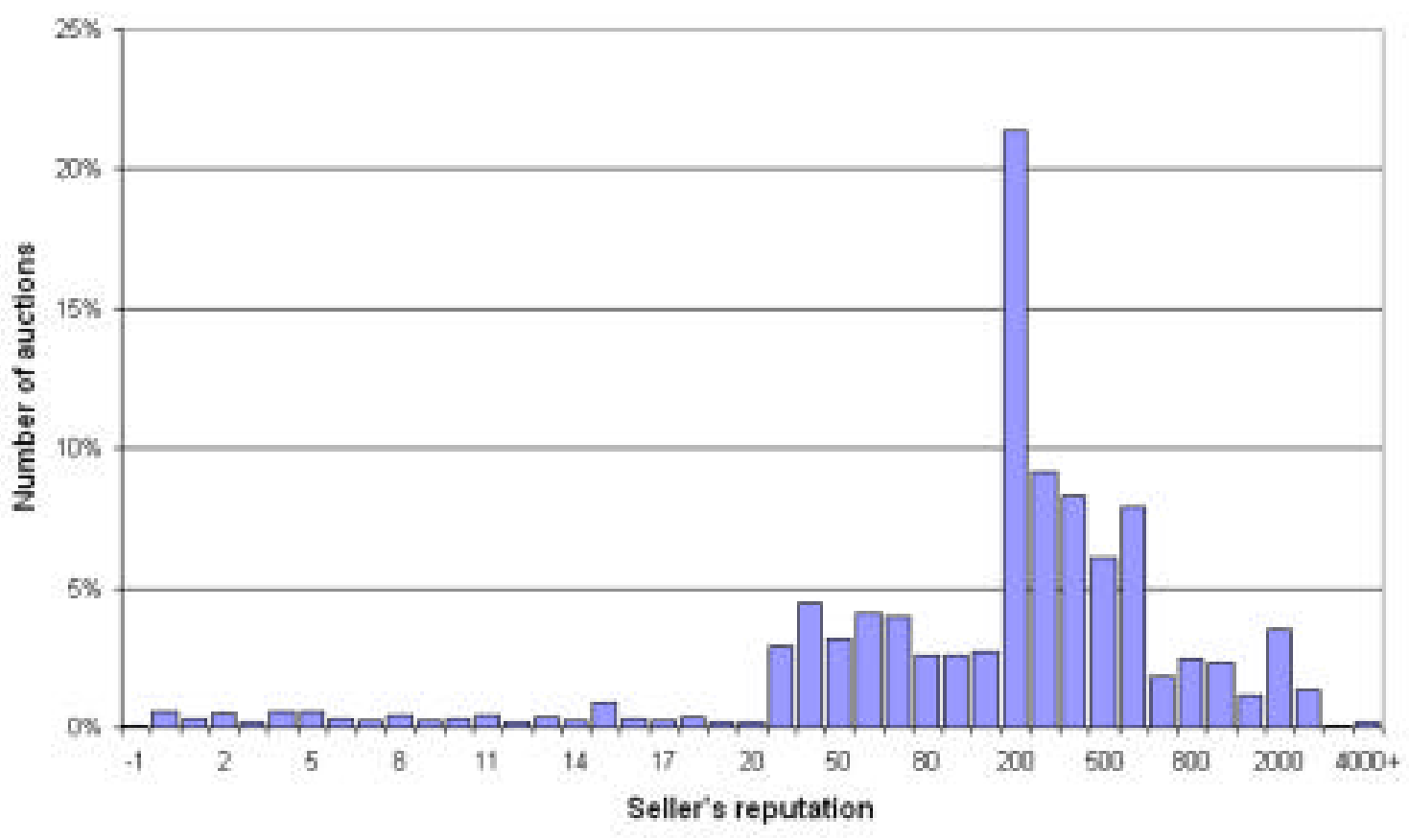


Chart 14 minbybookHisto

Histogram of the ratio of minimum bid to book value, for 461 Indian Head auctions

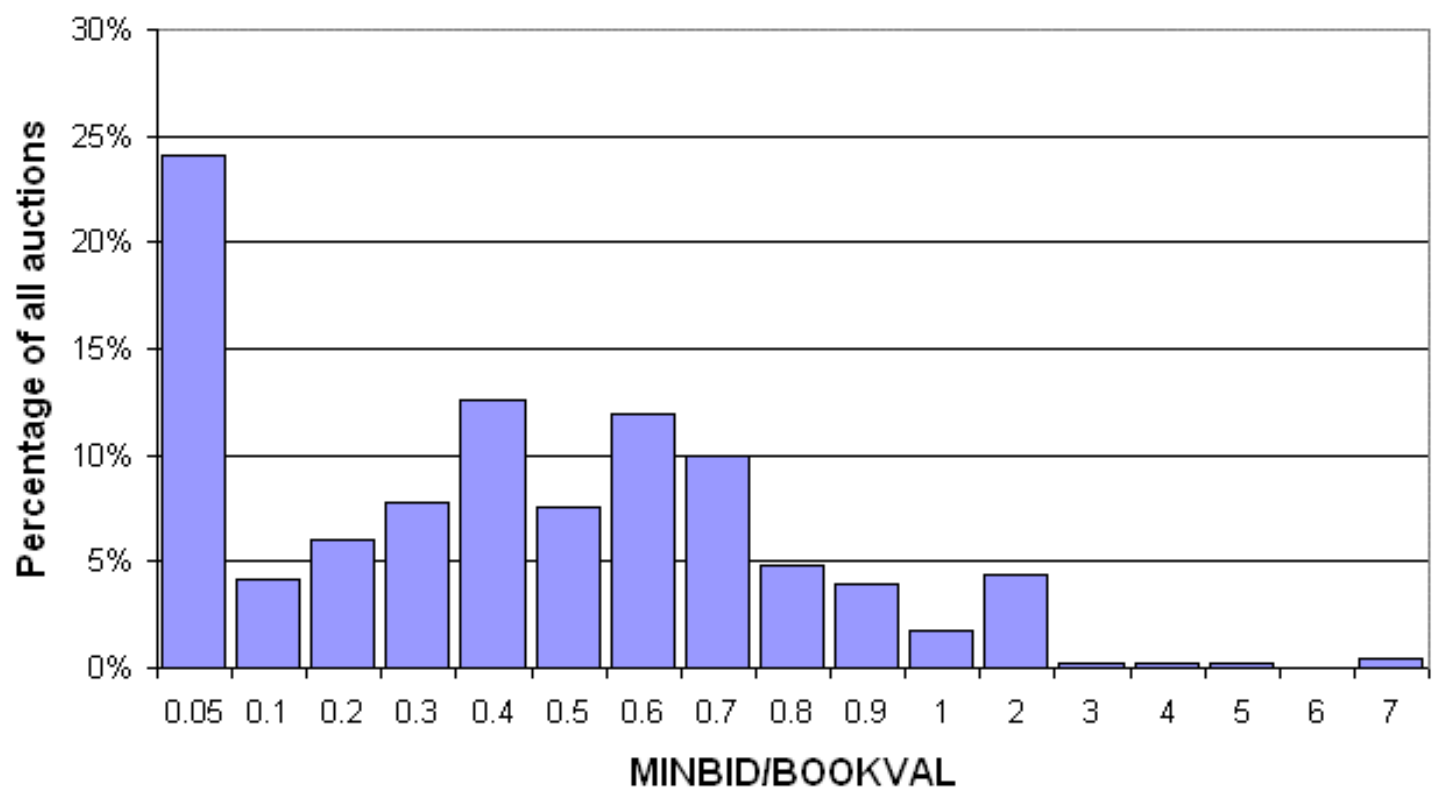

Chart 15 pricebyBookHisto

Histogram of price to book value ration, for the $\mathbf{2 8 5}$ Indian Head auctions that transacted

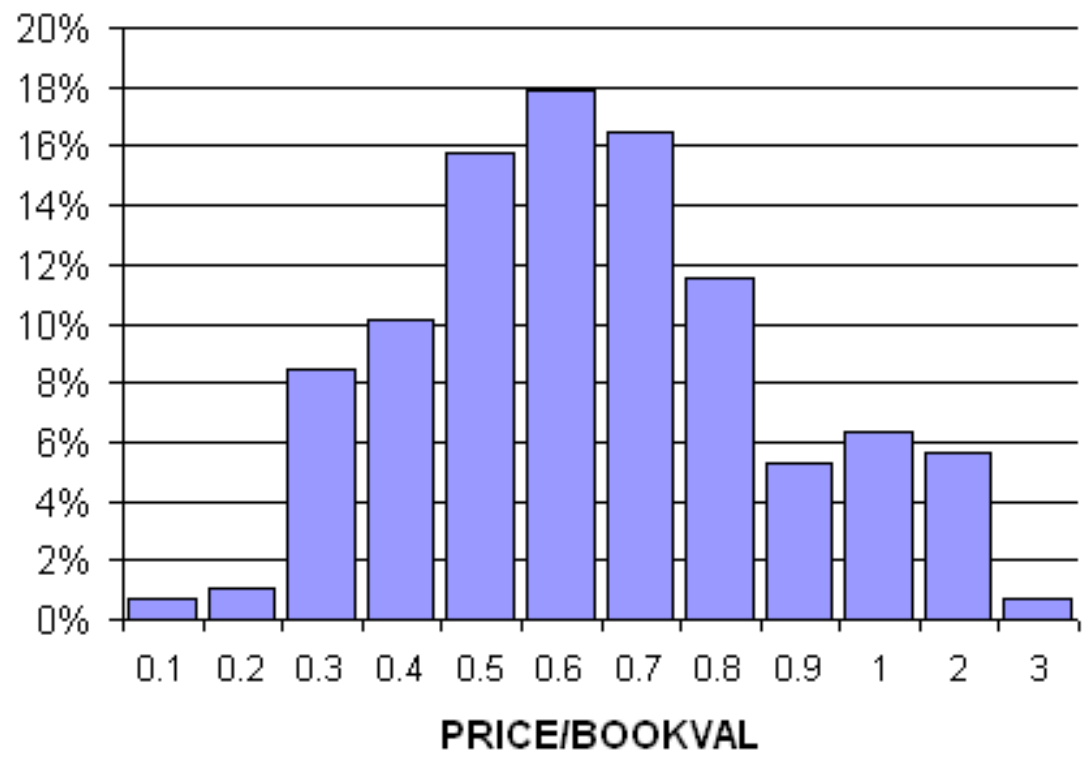




\section{Table 1. The determinants of price in eBay coin auctions.}

Dependent variable: $\ln (\mathrm{PRICE})$

\begin{tabular}{|c|c|c|c|c|c|c|}
\hline & $\begin{array}{l}\text { All cents } \\
\text { (no book }\end{array}$ & \multicolumn{3}{|c|}{$\begin{array}{l}\text { Uncirculated Indian cents, } \\
\text { with book values }\end{array}$} & $\begin{array}{l}\text { Restricted } \\
\text { sample: }\end{array}$ & $\begin{array}{l}\text { Restricted } \\
\text { sample: }\end{array}$ \\
\hline $\begin{array}{c}\text { In(BOOKVAL } \\
\text { (BO }\end{array}$ & - & $\begin{array}{l}.8144^{*} \\
(.0251)\end{array}$ & $\begin{array}{l}.8129^{\star} \\
(.0251)\end{array}$ & $\begin{array}{l}.8136^{\star} \\
(.0249)\end{array}$ & $\begin{array}{l}.8393^{*} \\
(.0255)\end{array}$ & $\begin{array}{l}.8422^{*} \\
(.0295)\end{array}$ \\
\hline In(MINBID) & $\begin{array}{l}.4076^{\star} \\
(.0054)\end{array}$ & $\begin{array}{l}.0065 \\
(.0127)\end{array}$ & $\begin{array}{l}.0083 \\
(.0127)\end{array}$ & $\begin{array}{l}.0084 \\
(.0127)\end{array}$ & $\begin{array}{l}.0330^{*} \\
(.0125)\end{array}$ & $\begin{array}{l}.0195 \\
(.0139)\end{array}$ \\
\hline RESERVE & $\begin{array}{l}1.247^{*} \\
(.0245)\end{array}$ & $\begin{array}{l}.1542^{*} \\
(.0622)\end{array}$ & $\begin{array}{l}.1601^{*} \\
(.0624)\end{array}$ & $\begin{array}{l}.1521^{*} \\
(.0619)\end{array}$ & $\begin{array}{l}.0684 \\
(.0615)\end{array}$ & $\begin{array}{l}.0775 \\
(.0670)\end{array}$ \\
\hline $\ln (\mathrm{POS}+1)$ & $\begin{array}{c}-.0195^{*} \\
(.0079)\end{array}$ & $\begin{array}{c}.0384 \\
(.0271)\end{array}$ & $\begin{array}{c}.0378 \\
(.0271)\end{array}$ & $\begin{array}{c}.0444 \\
(.0272)\end{array}$ & $\begin{array}{c}.0446 \\
(.0273)\end{array}$ & $\begin{array}{c}.0216 \\
(.0291)\end{array}$ \\
\hline $\ln (N E G+1)$ & $\begin{array}{l}.0085^{\star} \\
(.0148)\end{array}$ & $\begin{array}{c}-.1104^{*} \\
(.0461)\end{array}$ & $\begin{array}{c}-.1054^{*} \\
(.0462)\end{array}$ & $\begin{array}{l}-.1122^{*} \\
(.0460)\end{array}$ & $\begin{array}{l}-.1166^{*} \\
(.0471)\end{array}$ & $\begin{array}{l}-.0676 \\
(.0551)\end{array}$ \\
\hline NUMDAYS & $\begin{array}{l}.0610^{*} \\
(.0053)\end{array}$ & $\begin{array}{l}.0614^{*} \\
(.0133)\end{array}$ & $\begin{array}{l}.0610^{\star} \\
(.0133)\end{array}$ & - & $\begin{array}{l}.0417^{*} \\
(.0133)\end{array}$ & $\begin{array}{l}.0309^{*} \\
(.0156)\end{array}$ \\
\hline WEEKEND & - & - & $\begin{array}{l}.0652 \\
(.0561)\end{array}$ & - & - & - \\
\hline DAYS5 & - & - & - & $\begin{array}{l}-.0148 \\
(.0768) \\
\end{array}$ & - & - \\
\hline DAYS7 & - & - & - & $\begin{array}{l}.2188^{*} \\
(.0724)\end{array}$ & - & - \\
\hline DAYS10 & - & - & - & $\begin{array}{l}.3544^{*} \\
(.1019)\end{array}$ & - & - \\
\hline constant & $\begin{array}{l}1.041^{*} \\
(.0528)\end{array}$ & $\begin{array}{l}-.4050^{\star} \\
(.1756)\end{array}$ & $\begin{array}{l}-.4188^{*} \\
(.1788)\end{array}$ & $\begin{array}{l}-.1941 \\
(.1694)\end{array}$ & $\begin{array}{l}-.3721^{*} \\
(.1772)\end{array}$ & $\begin{array}{l}-.1915 \\
(.1971)\end{array}$ \\
\hline $\begin{array}{l}N \\
\mathrm{R}^{2}\end{array}$ & $\begin{array}{c}20,292 \\
.0979\end{array}$ & $\begin{array}{l}461 \\
.4908\end{array}$ & $\begin{array}{l}461 \\
.4920\end{array}$ & $\begin{array}{l}461 \\
4950\end{array}$ & $\begin{array}{l}334 \\
.8068\end{array}$ & $\begin{array}{l}262 \\
.7892\end{array}$ \\
\hline
\end{tabular}

In the first four models, the dependent variable $[\ln (\mathrm{PRICE})]$ is left-censored for those observations where the number of bids equals zero. In these cases, all we know is that the "latent" auction price is lower than the minimum bid amount. Therefore, these regressions are maximum-likelihood censored-normal regressions, where the censoring point for each observation is the minimum bid for that auction.

The last two models are limited to observations where bids were received, and thus we use ordinary least squares to estimate these models.

We add 1 to the POS and NEG variables before taking logarithms in order to avoid taking the logarithm of zero for some observations.

An asterisk $(*)$ indicates an estimate which is statistically significantly different from zero at the $5 \%$ level. 